Discussion Papers

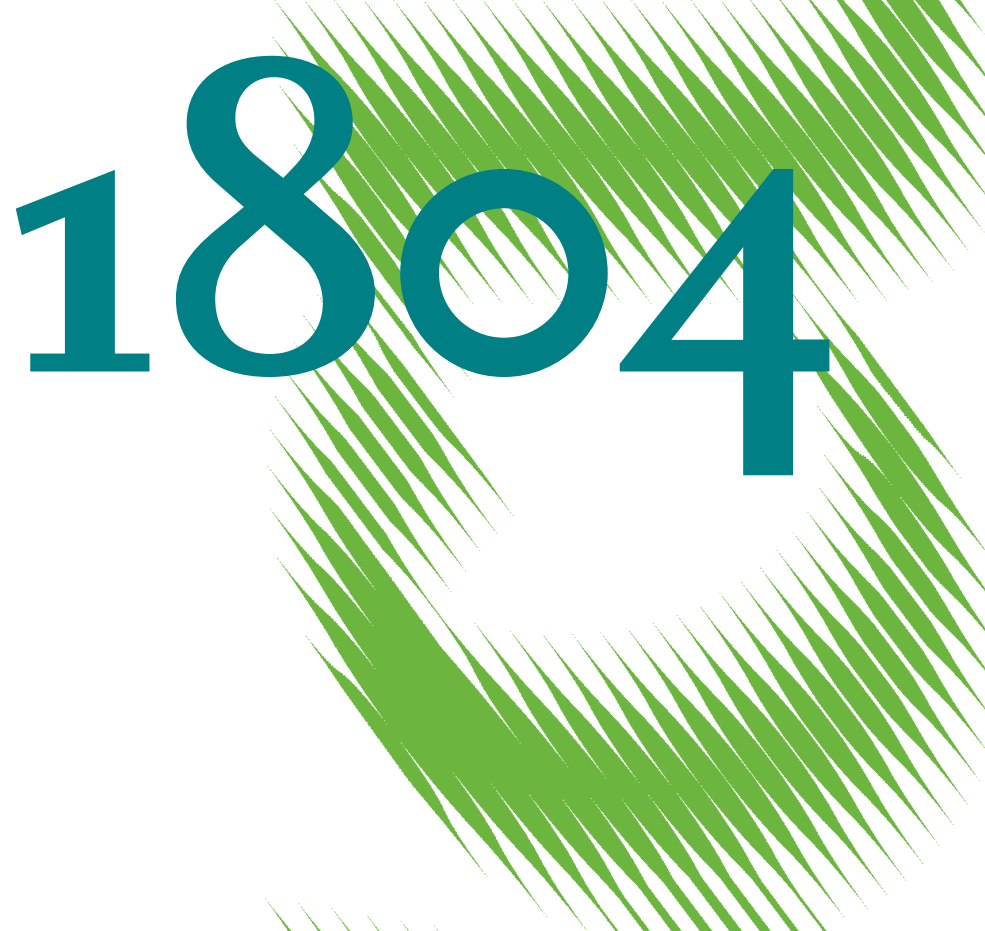

The War in Europe: Economic Costs of the Ukrainian Conflict 
Opinions expressed in this paper are those of the author(s) and do not necessarily reflect views of the institute.

IMPRESSUM

(C) DIW Berlin, 2019

DIW Berlin

German Institute for Economic Research

Mohrenstr. 58

10117 Berlin

Tel. +49 (30) $89789-0$

Fax +49 (30) $89789-200$

http://www.diw.de

ISSN electronic edition 1619-4535

Papers can be downloaded free of charge from the DIW Berlin website:

http://www.diw.de/discussionpapers

Discussion Papers of DIW Berlin are indexed in RePEc and SSRN:

http://ideas.repec.org/s/diw/diwwpp.html

http://www.ssrn.com/link/DIW-Berlin-German-Inst-Econ-Res.html 


\title{
The war in Europe: Economic costs of the Ukrainian conflict
}

\author{
Julia Bluszcz* and Marica Valente ${ }^{\dagger}$
}

\begin{abstract}
With more than ten thousand casualties, the 2014 Ukrainian war between pro-Russian separatists and the government in the Donbass region, Ukraine's productive core, has taken a severe toll on the country. Using cross-country panel data over the period 1995-2017, this paper quantifies the short-term causal effects of the Donbass war on Ukraine's GDP. Results from the counterfactual estimation by the synthetic control method show that Ukraine's per capita GDP foregone due to the war amounts to $15.1 \%$ on average for 2013-2017. Separate analysis for the affected provinces of Donetsk and Luhansk indicate an average causal effect of $43 \%$ for 2013-2016. Confoundedness checks obtained by iteratively estimating synthetic controls on the pre-war period to account for previous Ukrainian-Russian disputes show robustness of the results.
\end{abstract}

Keywords conflict, economic costs, Donbass, synthetic control

JEL Codes: D74, P16, C21, G14

\footnotetext{
*Department of Econometrics, Humboldt University Berlin.

${ }^{\dagger}$ Corresponding author: Department of Econometrics, Humboldt University Berlin, and Department of Energy, Transportation and Environment, German Institute for Economic Research (DIW Berlin), E-mail: mvalente@diw.de, tel.: +49-30-89789-507.
} 


\section{Introduction}

Military conflicts always entail large costs, including economic, social, political, psychological and environmental ones. A vast literature is devoted to the ex-post evaluation of the economic costs of conflict to assess the losses incurred by the states and the civil society. Starting from Keynes (1919), many studies show that war has persistent negative consequences on the welfare of the populations involved (see, e.g., Gates, 2012, Koubi, 2005, Abadie and Gardeazabal, 2003). To the best of our knowledge, this is the first empirical study to estimate the economic costs of the Ukrainian conflict in the Donbass region started in 2014.

The Donbass war is an armed conflict between anti-government groups of pro-Russian separatists and the Ukrainian government, taking place in the aftermath of the 2013 Euromaidan protests and the 2014 Ukrainian revolution. Located in eastern Ukraine, the Donbass region is considered Ukraine's productive core due to coal mining and highly productive heavy industry. Therefore, the Donbass war has taken a severe toll on Ukraine, especially in terms of production, employment, number of displaced persons, and civilian as well as military casualties (Angelovski, 2015). In this paper, we estimate the short-term economic costs of this conflict on Ukraine's per capita GDP.

Although GDP per capita is mainly an output and not a welfare measure (as argued by, e.g., Stiglitz et al. 2009, Soares, 2006), our analysis focuses on this outcome for two reasons. First, the Donbass is of considerable importance for Ukraine's production. Before the 2014 Ukrainian Revolution, the Donbass accounted for about a quarter of the country's exports and more than $15 \%$ of capital investment. As of August 2014, the industrial production dropped by $60 \%$ and $85 \%$ in the Donbass provinces of Donetsk and Luhansk, respectively, due to power cuts and railway disruptions (Havlik, 2014). Thus, due to the Donbass' strategic role in the country's economy and its large contribution to the GDP, we expect a major effect occurring on this variable. Second, since the Donbass war is still ongoing at the time of writing, it is difficult to give precise estimates of other types of costs due to lack of data. Thus, we consider foregone GDP as the main measure of welfare loss. This approach is also followed by, e.g., Costalli et al. (2017), Horiuchi 
and Mayerson (2015), and Abadie and Gardeazabal (2003), who find strong significant post-conflict average GDP per capita losses ranging from 8.6\% to $17.5 \%$ (see Gardeazabal, 2010, for a review of older studies).

The Donbass war is an especially interesting case study also in the prospects for conflict resolution. In particular, the uniqueness of this conflict lies in being a hybrid war (Lanoszka, 2016, Reisinger and Golts, 2014). Whilst a proper definition is lacking, this usually refers to conflicts among countries not openly fighting against each other (Monaghan, 2016). Further, hybrid wars do not usually involve national armies but rather non-state actors who are, however, often supplied and trained by official armed forces. As a matter of fact, despite more than ten thousand casualties and continuous fights, neither Ukraine nor any other entity declared the war status: the Ukrainian government referred to it as an anti-terrorist operation, and, on the other side, Russia admitted that intelligence military forces were sent to Ukraine, but denies the use of regular troops (Walker, 2015). As a result, although there are many signs indicating Russia's involvement in the Donbass war (Rácz, 2015), the lack of undeniable confirmation from Kremlin's side complicates the relationship between both countries and hinders any mitigation of the conflict.

Empirically, we use the Synthetic Control Method (SCM) to estimate causal effects of this war on Ukraine's GDP per capita (Abadie et al., 2010). Building on the potential outcomes approach (Rubin, 1974), we obtain the counterfactual, "synthetic", Ukraine as a weighted average of control (unaffected) countries with weights reflecting the resemblance of both the outcome variable and outcome predictors in Ukraine before the war's outbreak. A country-level panel data over the period 1995-2017 is used for the analysis. Causal effects are estimated by computing the yearly difference in GDP per capita between Ukraine and its synthetic counterpart after the eruption of the war. Moreover, we apply the SCM iteratively to check for other potential shocks taking place in Ukraine before the Donbass war, in particular, the 2004 Orange Revolution, and the 2009 gas dispute with Russia. Finally, since the war is likely to affect the Ukrainian territory unequally, we further conduct a similar analysis for the Donbass provinces of Donetsk and Luhansk. 
Results indicate that due to the Donbass war, whose start is set to 2013, Ukraine's foregone GDP per capita amounts to $15.1 \%$ on average in the post-war period and, respectively, $5.23 \%$ (460.26\$), $9.18 \%$ (832.96\$), $19.63 \%$ (1823.78\$), $19.80 \%$ (1893.38\$), $21.67 \%$ $(2184.13 \$)$ in $2013,2014,2015,2016$, and 2017 . The obtained estimates are validated by a series of robustness checks. After iteratively applying the SCM, we find that gas disputes led to an overestimation of the previous causal effects by 2.4 percentage points $(128.04 \$)$ on average. Instead, our findings show that the Orange Revolution did not considerably influence Ukraine's economic development and, thus, it did not confound the obtained causal estimates of the war. Lastly, results from the regional analysis confirm the devastating effect of the war for the Donbass area. In particular, we estimate that Donetsk's per capita Gross Regional Product (GRP) dropped by $43 \%$ (4630\$) on average due to the war. Estimates for Luhansk are of even larger magnitude with a per capita GRP average decrease of $52 \%(3326 \$)$.

The remainder of the paper is organized as follows: Section 2 outlines the synthetic control approach used to estimate the causal effects under study. Data are described in Section 3 . Section 4 shows the results and discusses limitations of our analysis. Section 5 concludes and provides implications of this study.

\section{Methodology}

This section presents the SCM as developed by Abadie and Gardeazabal (2003) and later refined by Abadie et al. (2010). In addition to the identification and estimation strategy, we discuss advantages of the SCM as well as its limitations especially related to inference. The true causal impact of a conflict on per capita GDP is given by outcome differences between Ukraine after the war and its counterfactual without the war. The SCM builds upon the potential outcomes approach (Rubin, 1974) to estimate this counterfactual, "synthetic" Ukraine, by weighting units in the control group before the war to resemble Ukraine in all outcome-relevant variables, in particular observed time-varying covariates and a set of pre-intervention outcomes. Once the control group is weighted to predict Ukraine's per capita GDP path before the war, post-war differences would only be due 
to the war if Ukraine's per capita GDP is accurately fitted by the synthetic control prewar. Average causal effects for Ukraine, i.e. the Average Treatment effect on the Treated (ATT), can be computed as the post-war average difference between the observed outcome of Ukraine and synthetic Ukraine (Abadie et al., 2010).

Consider $i=1, \ldots, J+1$ countries and $t=1, \ldots, T$ time periods with $1 \leq T_{0}<T$ pre-war periods, let $Y_{i t}^{N}$ be the per capita GDP of Ukraine $i=1$ in time $t$, if not exposed to the war. Let Ukraine be the only recipient of the war, and let the other $J$ countries be unaffected by the conflict. Note that SCM assumes that no country anticipates the war's outbreak before the time period $T$, and that there are no spillover effects of the conflict on the $J$ control regions after the war (known as Stable Unit Treatment Value Assumption, SUTVA). Consider a $(J \times 1)$ vector of optimal weights $W^{*}=\left(w_{2}^{*}, \ldots, w_{J+1}^{*}\right)^{\prime}$ with $w_{j} \geq 0$ for $i=2, \ldots, J+1$ and $w_{2}+\cdots+w_{J+1}=1$ for $J$ control units such that $\hat{Y}_{1 t}^{N}=\sum_{j=2}^{J+1} w_{j}^{*} Y_{j t}$. The aim of this analysis is to obtain the ATT defined as:

$$
\hat{\alpha}_{1 t}=\frac{1}{T-T_{0}} \sum_{t>T_{0}}\left[Y_{1 t}-\sum_{j=2}^{J+1} w_{j}^{*} Y_{j t}\right] .
$$

The estimation of the optimal $W^{*}$ follows a nested optimization procedure. First, an inner optimization minimizes the Euclidean distance between $X_{1}$ and $X_{0} W,(r+k) \times 1$ and $(r+k) \times(J)$ matrices, respectively, containing $k$ covariates and $r$ linear combinations of pre-war outcomes used as predictors 2.0 .2$)$ :

$$
W^{*}=\underset{W}{\arg \min }\left\|X_{1}-X_{0} W\right\| v=\sqrt{\left(X_{1}-X_{0} W\right)^{\prime} V\left(X_{1}-X_{0} W\right)},
$$

where $V$ is a $(r+k) \times(r+k)$ symmetric diagonal matrix with non-negative components, in which the diagonal elements $v=\left(v_{1}, \ldots, v_{r+k}\right)$ are the predictor weights assigned to the fitted pre-intervention variables. In an outer optimization, $V^{*}$ can be estimated such that the Mean Squared Error (MSE) of labor market outcomes is minimized for pre-treatment periods according to $V^{*}=\arg \min _{V}\left(Y_{1}-Y_{0} W^{*}(V)\right)^{\prime}\left(Y_{1}-Y_{0} W^{*}(V)\right)$, where $Y_{1}$ and $Y_{0}$ refer to linear combinations of pre-war outcomes of Ukraine and control countries, which can be, e.g., averaged over some pre-war periods. Once $W$ control countries' and $V$ predictors' 
weights are estimated, the outcome of the synthetic Ukraine is computed as a weighted linear combination of control countries' outcomes as $\sum_{j=2}^{J+1} w_{j}^{*} Y_{j t}=\hat{Y}_{1 t}^{N}$. For $t>T_{0}$, the average difference between the latter and $Y_{1 t}$, the outcome of Ukraine, is the estimated ATT in (2.0.1).

The SCM identifying assumptions are twofold. First, the outcome of all countries is required to follow a linear model, like, e.g., a factor model including interactive fixed effects that capture time-varying unobserved heterogeneity (see Abadie et al., 2010, and Ahn et al., 2013). Since Abadie and Gardeazabal (2003) introduce the SCM using GDP as the dependent variable, we consider this assumption as fulfilled (see, e.g., Costalli et al., 2017, Horiuchi and Mayerson, 2015 for similar choices). Second, there exists optimal (nonnegative) weights (smaller than one) that build the synthetic control as a convex linear combination of control countries matching a set of covariates and outcomes pre-war. This is violated in the presence of interpolation bias, i.e., if the synthetic control obtains weights for countries that largely differ in terms of unobservable confounders that may trigger any change in the outcome. In our context, confounders could consist of, e.g., unobserved time-varying factors driving both GDP and the conflict. To avoid the interpolation bias we restrict the control group to countries of the former Soviet Union and Eastern Bloc not recipient of the Donbass war or other shocks, as they most accurately reflect the Ukrainian economy, and we exclude Russia because it is part of the Donbass war, of the 2014 annexation of Crimea, and the consequent economic sanctions imposed by the European Union and the United States. Therefore, provided that the number of pre-war periods is large and interpolation bias is not present, the synthetic control approximately fits Ukraine also in its individual time-varying heterogeneity (Abadie et al., 2010). In such cases, the SCM provides unbiased estimates of the counterfactual with more identification power than traditional regression methods accounting only for time-invariant unobserved differences (Gobillon and Magnac, 2016).

To assess potential confounding events occurring in Ukraine before the war, we apply the SCM iteratively for various time periods to correct the causal estimates for other potential shocks, namely, the 2004 Orange Revolution and the 2009 gas disputes with Russia. 
Since this setting is not suitable for large-scale (asymptotic) inferential techniques, placebo inference, based on permutation tests, is performed by building a synthetic control for each country in the control group, and estimating the corresponding ATT (Abadie et al., 2010). Empirical p-values are then computed as the probability to obtain ATTs as large as the treated unit's, i.e., $\frac{\sum_{j=1}^{J+1} \mathbf{1}\left(\hat{\alpha}_{j} \geq \hat{\alpha}_{1}\right)}{J+1}$.

In addition to placebo tests, a way to test for significance of our results is to condition on the quality of the average pre-war fit to obtain the likelihood of an abnormal average post-war gap as in Seifert and Valente (2017). Thus, we analyze the average post-war gap, i.e., the ATT, for each country given the corresponding average pre-war gap, computed as Mean Absolute Deviation (MAD). A very small MAD (large ATT) indicates a very good fit before the war (very bad fit after the war). Thus, we expect Ukraine to display a very large ATT in absolute terms and a low level of MAD. This is not the case for those placebos expected to have similarly high (or small) ATT and MAD if the control countries are indeed not impacted by the war. Thereby, after estimating synthetic controls for every control country, we compute the respective ATT and MAD. Formally, the ATT is expressed as $\hat{\alpha}_{i}$ and the MAD as $\frac{1}{T_{0}} \sum_{i=1}^{J+1}\left|Y_{i t}-\hat{Y}_{i t}^{N}\right|$ for $i=1, \ldots, J+1$ and $\hat{Y}_{i t}^{N}$ being the synthetic control estimated for every region $i$. This inferential test obtains the empirical p-values as $\frac{\sum_{j=1}^{J+1} \mathbf{1}\left(A T T_{j} \geq A T T_{1}\right)}{J+1}$ s.t. $M A D_{j} \leqslant M A D_{1}$ for every $j=1, \ldots, J+1$.

Note that this test differs from the inferential technique performed, e.g., by Abadie et al. (2010), who compute the ratio between post-intervention and pre-intervention MSE. In this case, the numerator results to be inflated in the presence of, e.g., a large causal effect in one single post-war period, as squaring post-war gaps assigns a higher weight to exceptionally large deviations. On the contrary, a counterweight of this effect in the denominator for pre-intervention MSE is unlikely to occur as every placebo country with a much (typically, five to three times) higher MSE than the one of the treated unit is excluded from the computation of the p-values. Motivated by the above as well as by recommendations in Arkhangelsky et al. (2019), Ferman and Pinto (2017), and Firpo and Possebom (2016), MAD-based inference is also presented.

In conclusion, the SCM allows for a multidimensional unobserved heterogeneity, i.e., for 
multiple interactive effects, not just additive ones as imposed, e.g., in the difference-indifferences (DID) setting (Gobillon and Magnac, 2016). In practice, interactive effects can be considered time-varying fixed effects like, for example, country-specific variations in strategic alliances. Therefore, the SCM generalizes the DID method allowing to clearly identify the causal effect of the Donbass war on GDP per capita, disentangling the ATT from all other unobserved time-varying confounding factors present at cross-sectional level.

\section{Data}

We use yearly country-level panel data over the period 1995-2017 obtained from the World Development Indicators database of the World Bank. The dependent variable used in the SCM analysis is the GDP per capita (GDPpc) in 2011 dollars (PPP). Further, outcome predictors used to match Ukraine in the pre-war period are chosen based on literature review (e.g., Abadie and Gardeazabal, 2003). We include inflation measured by consumer price index due to the prevalence of hyperinflation in post-Soviet states, and its influence on economic development. Further, we control for domestic investment with gross fixed capital formation (GFCF) as a percentage of GDP, and we measure the dependence on trade with Russia as the sum of share of exports and imports with the Russian Federation in countries' total international trade (TradeDep). Finally, to account for political and socio-economic resemblance, we also include the Human Development Index (HDI) which is a composite indicator of life expectancy, education, and per capita income, as well as the Polity variable from the Polity IV project dataset in which values equal to $10(-10)$ indicate a strongly democratic (autocratic) regime (Marshall, 2017). In the SCM estimation, we match on covariates' averages over the 1995-2012 period, and on two outcome lags. The following Table I provides data descriptive statistics, while the variables' full description can be found in Table B.1 in the Appendix B. 


\begin{tabular}{lrccc}
\hline & Mean & Standard Deviation & Maximum & Minimum \\
\hline TradeDep & 0.15 & 0.15 & 0.76 & 0.01 \\
GFCF & 23.79 & 6.37 & 57.71 & 5.39 \\
GDPpc & 14032.00 & 8509.13 & 31339.00 & 1043.00 \\
Inflation & 18.45 & 59.98 & 1058.00 & -8.52 \\
Polity & 4.96 & 6.25 & 10 & -8 \\
HDI & 0.74 & 0.08 & 0.81 & 0.53 \\
\hline
\end{tabular}

Table I. Descriptive statistics of variables.

The SCM makes a crucial assumption that Ukraine's GDP per capita and all its predictors have to lie within the convex hull spanned by the countries from the donor pool, such that a convex combination of the control countries can actually resemble the treated unit. Figure 1 shows evidence on the presence of such common support.

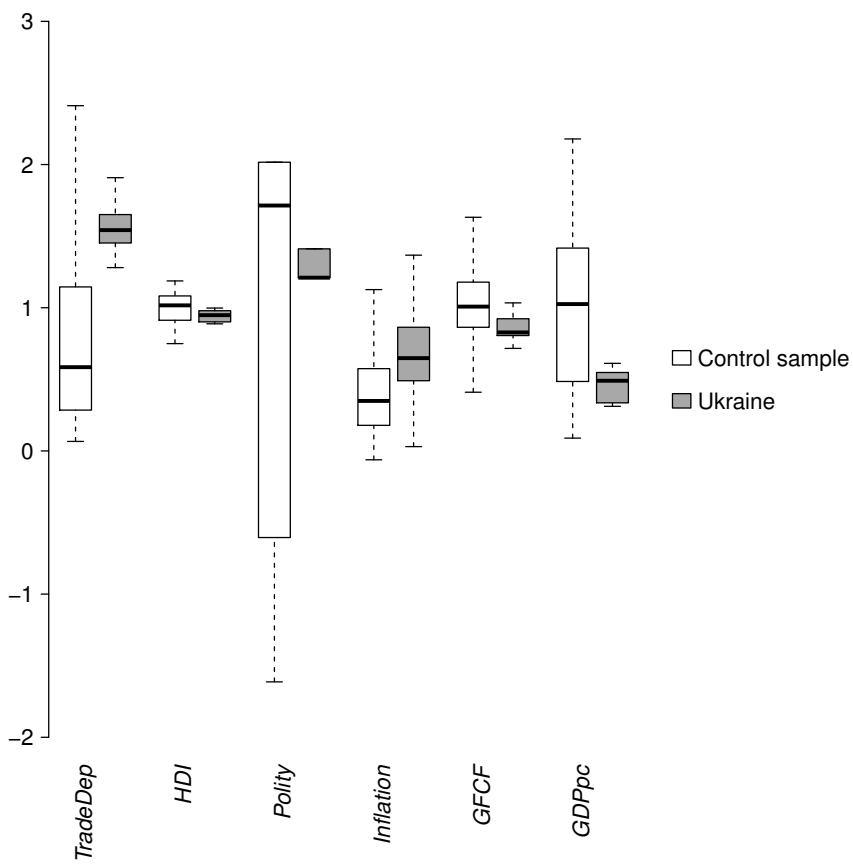

Figure 1. Boxplots of mean-corrected variables.

As outlined in Section 3, synthetic Ukraine is built as a weighted average of former Soviet Union and Eastern Bloc countries to most accurately resemble its unobserved fiscal and economic conditions over time. We also excluded countries experiencing other shocks in the considered pre-war period. As a result, the control group comprises 17 countries, which are listed in Table II of Section 4 .

Regional SCM estimates are obtained with data from the State Statistics Service of Ukraine, and the first available period is 2004. Limited data availability constrains the 
choice of the variables included. These are exports of commodities, capital investment, unemployment rate, and per capita GRP. A detailed description of the data is to find in Table B.2 in the Appendix B. The values of regions' GRP and capital investment are transformed from the Ukrainian currency (UAH) into international 2011 dollars using the exchange rates given in Table B.8 in the Appendix B.

A last note regarding the onset of the Donbass war. The war burst out in 2014, however, it was preceded by the 2013 violent Euromaidan protests and a period of high political instability. For this reason, we assign the year 2013 as the start of the war. Consequently, we estimate the counterfactual over 18 pre-war periods, and we predict the outcome over five post-war periods. As specified in Section 3, a precise and robust fit between actual and counterfactual outcome over the whole pre-war period is necessary to guarantee the validity of the counterfactual estimate itself.

\section{Results}

Using the SCM, we first show how synthetic Ukraine fits Ukraine's GDP per capita before the war to provide an unbiased counterfactual after the war, and we compute causal effects. Second, we assess statistical significance by placebo tests, and we perform a set of confoundedness as well as sparsity checks. Third, using analogous analyses, we provide further evidence on the war's causal effects for Ukraine's most affected regions.

Table II shows that synthetic Ukraine is best reconstructed as a weighted average of four countries, namely, Armenia, Bulgaria, Moldova, and Slovenia - with Moldova and Armenia yielding the highest weights. 


\begin{tabular}{lccc}
\hline \hline Country & Weight & Country & Weight \\
\hline Armenia & 0.333 & Latvia & 0 \\
Azerbaijan & 0 & Lithuania & 0 \\
Belarus & 0 & Moldova & 0.452 \\
Bulgaria & 0.152 & Poland & 0 \\
Czech Republic & 0 & Romania & 0 \\
Estonia & 0 & Slovak Republic & 0 \\
Hungary & 0 & Slovenia & 0.063 \\
Kazakhstan & 0 & Tajikistan & 0 \\
Kyrgyz Republic & 0 & & \\
\hline \hline
\end{tabular}

Table II. Ukraine's control sample with corresponding weights.

Furthermore, Table III displays the results of the estimation, and shows that synthetic Ukraine accurately reproduces mean values of the covariates before the war.

\begin{tabular}{lccc}
\hline \hline \multirow{2}{*}{ Covariate } & \multicolumn{2}{c}{ Ukraine } & \\
\cline { 2 - 3 } Inflation & Real & Synthetic & Control sample \\
\hline GFCF & 20.44 & 23.04 & 20.72 \\
TradeDep & 0.23 & 22.89 & 24.17 \\
HDI & 0.70 & 0.68 & 0.14 \\
Polity & 6.50 & 6.83 & 0.74 \\
GDPpc(2000) & 4797.38 & 4797.03 & 4.78 \\
GDPpc(2012) & 8322.17 & 8538.05 & 10650.16 \\
\hline \hline
\end{tabular}

Table III. GDP per capita predictor means. Note that all variables are averaged for the 1995-2012 period except for lagged values of GDP per capita.

Figure 2 displays the trends of per capita GDP of Ukraine and its synthetic counterpart. It clearly shows that both follow a very similar path until 2012 and deviate considerably afterwards. It is estimated that the difference between observed and synthetic GDP per capita amounts to $15.1 \%$ on average in the post-war period and, respectively, $5.23 \%$ (460.26\$), $9.18 \%$ (832.96\$), 19.63\% (1823.78\$), 19.80\% (1893.38\$), and 21.67\% (2184.13\$) in 2013, 2014, 2015, 2016, and 2017. 


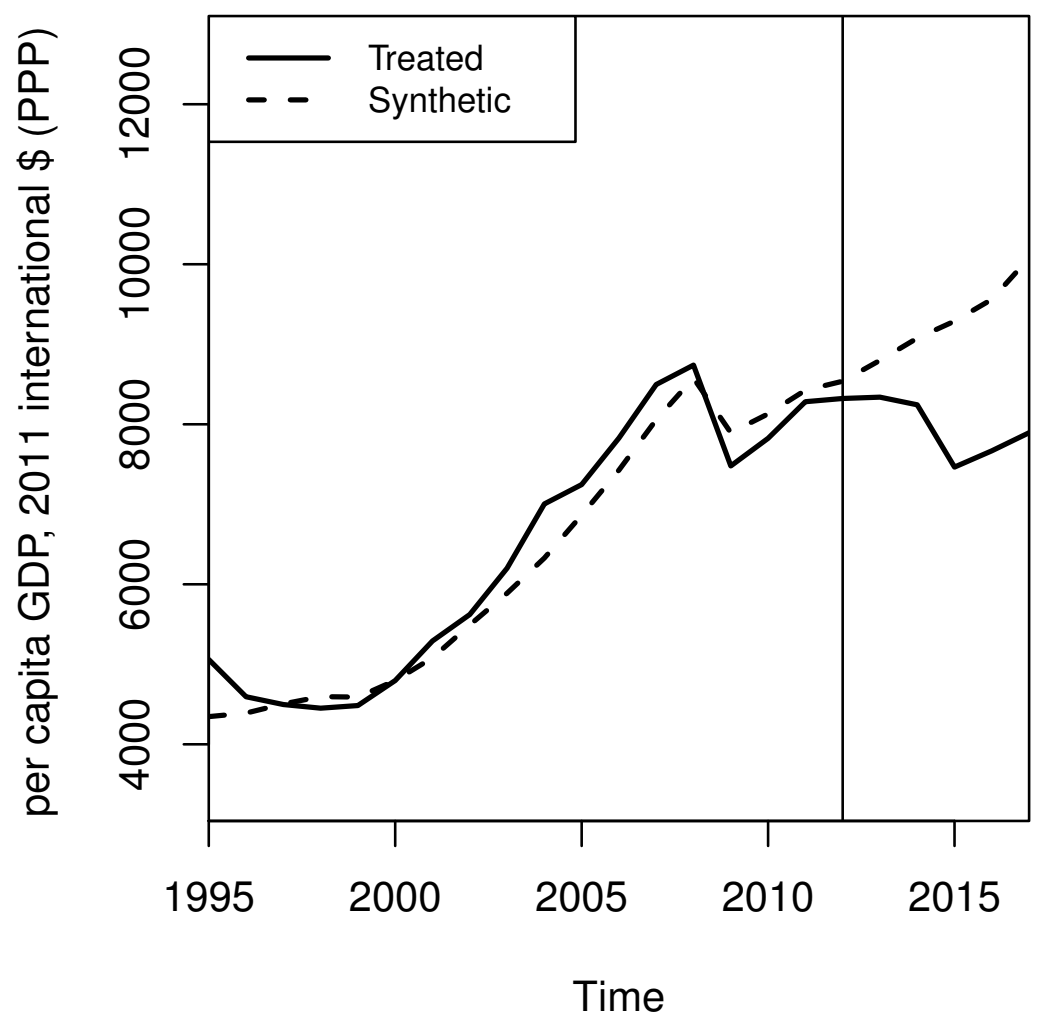

Figure 2. Trends in GDP per capita: Ukraine vs. synthetic Ukraine.

The SCM does not allow for usual large sample inferential techniques. Instead, it provides a framework for placebo tests. Figure 3 shows the graphical representation of placebo test for Ukraine and control countries. Countries with a bad fit before the war are excluded from the placebo analysis, in particular, we discard those with MSE five times higher than the one obtained for Ukraine (as suggested by Abadie et al., 2010). As a result, we exclude six countries, i.e., Azerbaijan, Czech Republic, Estonia, Poland, Slovenia, and Tajikistan from the plot, which leaves 11 remaining control countries. 


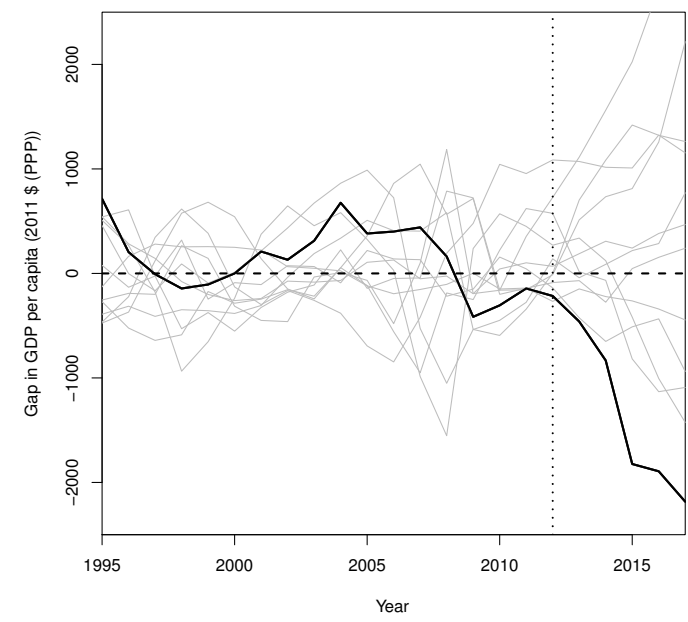

Figure 3. Gaps in GDP per capita in Ukraine and placebo gaps. Countries with poor pre-war fit excluded.

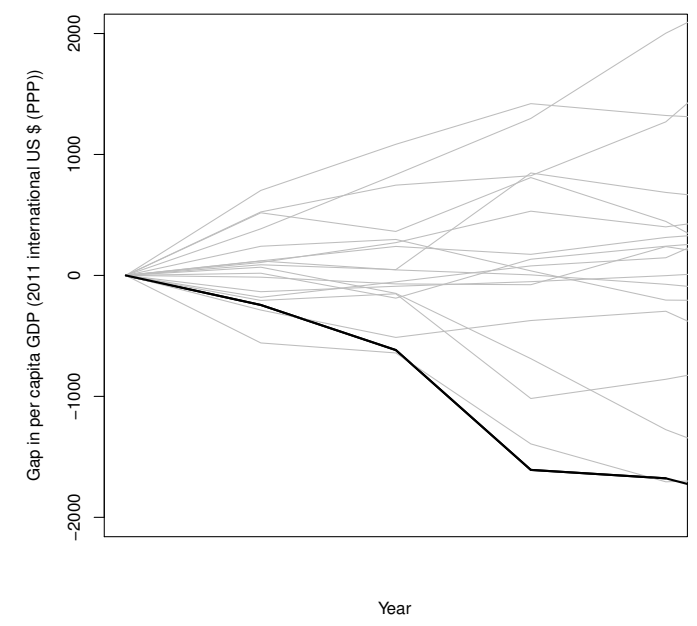

Figure 4. Gaps in GDP per capita in Ukraine and placebo gaps. Values are adjusted with respect to 2012 gaps.

Based on the graphical assessment of Figure 3, it can be concluded that the effects of the Donbass war on the Ukrainian economy are statistically significant at $9 \%$ level, which is the maximum level that we can reach given the size of our control group. Further, we adjust the placebo lines with respect to their 2012 values (Fig. 4). Also in this case, similar conclusions can be drawn. Further, we account for the goodness of fit of the placebos before the war by computing post-/pre-war MSE ratios. Figure 5 shows that Ukraine presents the second biggest ratio, yielding a statistical significance level of 11\%. As discussed in Ferman and Pinto (2017), previous placebo tests might be subject to size distortions. Therefore, we condition placebo tests on the mean error before the war without squaring its size, as suggested by Seifert and Valente (2017). This plot allows not only to compare the relative size of prediction errors in both pre- and postperiods but also their direction. Ukraine lies at the very bottom of the graph and in the middle of the x-axis. This implies that while Ukraine's pre-war mean prediction error is approximately zero, its post-war value, i.e., the causal effect, is very large and negative, yielding a statistical significance level of $5 \%$. 


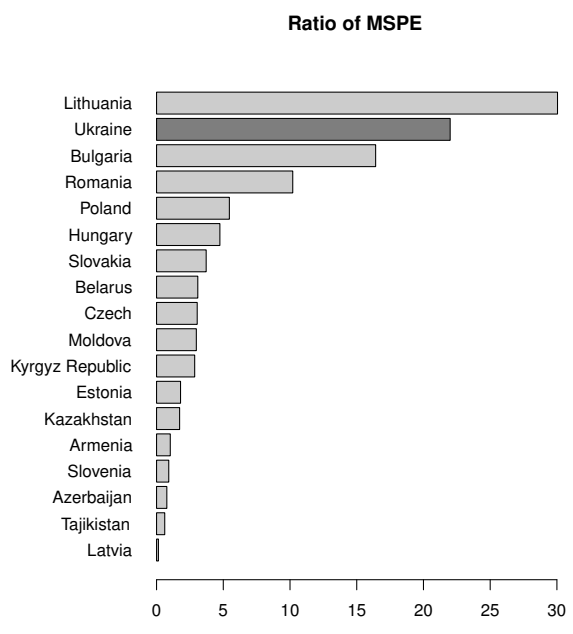

Figure 5. Ratio of mean squared prediction error in post- and pre-war periods.

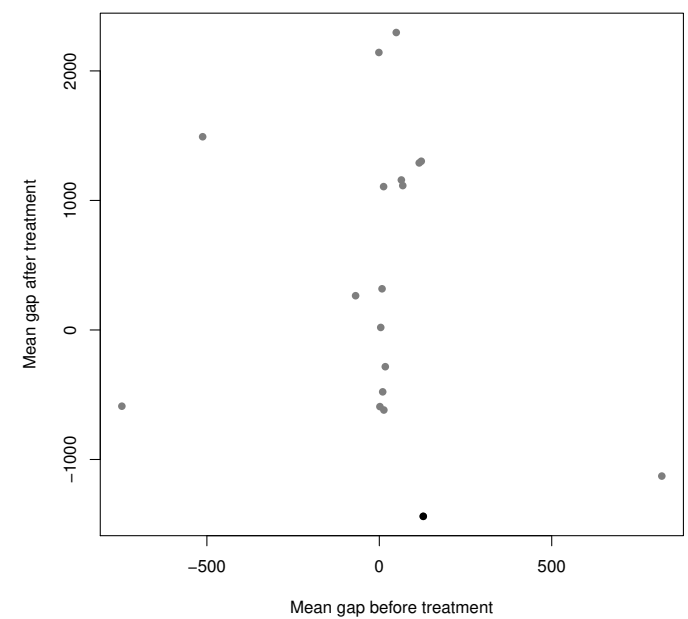

Figure 6. Scatterplot of mean prediction errors in post- and pre-war periods.

\subsection{Robustness checks}

To check whether the estimated synthetic Ukraine is robust against different linear combinations of country weights, we perform a leave-one-out (LOO) estimation. This means we iteratively build synthetic Ukraine excluding one control unit at the time (see Fig. 10 in the Appendix A). Results are shown to be robust to the exclusion of any particular country from the control group, and, as expected, estimation results mostly react to the exclusion of Moldova which obtained the highest weight in the original estimation.

Moreover, we perform confoundedness checks obtained by iteratively estimating synthetic controls on the pre-war period to account for previous Ukrainian-Russian disputes. This allows to verify if Ukraine's exposure to other external shocks also affects its outcome path. In particular, we analyze two events: the 2009 gas disputes with Russia, and the 2004 Orange Revolution. For this purpose, we iterate the SCM moving the treatment period $T_{0}+1$ to 2009 and 2004, respectively, and restricting the time frame to $T=2012$ to exclude effects of the Donbass war.

The Orange Revolution is a series of political protests leading to a period of political instability that could have caused a slowdown in Ukraine's GDP. However, estimation results show that this was not the case (see Fig. 11 and 12 in the Appendix A). 
Russian-Ukrainian gas disputes in 2009 represented a trade conflict over gas prices and their terms of export. Since no agreement was reached, Russia interrupted gas supplies to Ukraine which served as a transit country for Europe. Counterfactual estimation reveals a gap between observed and synthetic outcomes in 2009, indicating that Ukraine's GDP per capita would have been higher without the shock (see Fig. 14 in the Appendix A). In particular, gas disputes cause a one-time shock without long-lasting effects, namely, a level change in outcome in 2009 after which trends are parallel again. Placebo tests indicate that causal effects are significant at $10 \%$ level. Yet, these estimates may be confounded by two factors. First, gas prices increased after 2009, potentially affecting the GDP of control countries. This would lead to a bias in the SC due to violation of the no spillover assumption (SUTVA). Second, the effects of the 2009 financial crisis cannot be disentangled from those of the gas disputes.

Although the 2009 gap may not be entirely attributable to the gas disputes, we compute the confounding effects of the shock on the causal effects of the Donbass war. Being fairly constant for 2009-2012, outcome gaps caused by gas disputes $\left(\hat{\Delta}_{\text {gas }}\right)$ are substracted from the per capita GDP values of synthetic Ukraine in consecutive years, and the Donbass war's causal effects are adjusted as shown in Table IV These results, also displayed in Figure 13 in the Appendix A, suggest that the 2009 events lead to the overestimation of causal effects of the conflict by an average of 2.4 percentage points (128.04\$). As a result, the lower-bound for Ukraine's per capita GDP foregone due to the war amounts to $12.7 \%$.

\begin{tabular}{ccccc}
\hline \hline Year & Per capita GDP & Original loss & Loss incl. 2009 effects & Difference \\
$\mathrm{t}$ & $Y_{1 t}$ & $\hat{Y}_{1 t}^{N}-Y_{1 t}$ & $\hat{Y}_{g a s, t}-Y_{1 t}$ & \\
\hline 2013 & 8338.92 & 460.26 & 308.08 & 152.17 \\
2014 & 8243.47 & 832.96 & 669.26 & 163.70 \\
2015 & 7456.93 & 1823.78 & 1681.85 & 141.93 \\
2016 & 7668.10 & 1893.38 & 1805.65 & 87.73 \\
2017 & 7894.39 & 2184.13 & 2089.46 & 94.67 \\
\hline Average & 7921.96 & 1438.90 & 1310.86 & 128.04 \\
\hline \hline
\end{tabular}

Table IV. Per capita GDP differences between Ukraine and its synthetic control including effects of 2009 gas disputes with Russia (in 2011 international dollars, PPP).

\footnotetext{
${ }^{1}$ Causal effects of the gas disputes are computed as $\hat{\Delta}_{g a s}=1 / 4 \sum_{t=2009}^{2012} Y_{1 t}-\hat{Y}_{1 t}^{N}$, and the corrected counterfactual outcome accounting for such shock is $\hat{Y}_{g a s, t}=\hat{Y}_{1 t}^{N}-\hat{\Delta}_{\text {gas }}$ for $t>2012$.
} 


\subsection{Regional synthetic control estimates}

Since the Donbass war is limited to the territory of only two out of 24 Ukrainian provinces, we estimate the impact of the war on the respective GRP. Results from this estimation would also serve as a reliability check for the causal effects obtained at country level.

The control group includes 22 Ukrainian regions with the exclusion of Kyiv City because its economy differs considerably from those of the other regions. ${ }^{2}$ The complete list of the control units can be found in Table B.4 in the Appendix B.

For the estimation, we use regional panel data from 2004 to 2016. As for the countrylevel estimation, the treatment is assigned in 2013 to account for anticipation effects. We suspect that although armed conflicts did not start before 2014, there might have been regional tensions and hostilities that influenced social and economic living conditions of the local population. As a result, we match on nine pre-war periods to predict four post-war periods.

Compared to the country-level estimation, assumptions for the regional case are weaker, in particular, SUTVA. However, obtaining plausible causal estimates seems likely because Donetsk and Luhansk are the only regions directly affected by the fights.

Table B.4 in the Appendix reports the estimated weights, while Tables B.5 and B.6 show average values of covariates for the Donbass provinces, their synthetic counterparts, and the whole control sample. It can be inferred that weighted averages accurately reconstruct all the outcome-relevant characteristics of the affected units.

Additionally, Figures 7 and 8 plot the values of GRP per capita for Donetsk and Luhansk along with their synthetic counterparts. While in both cases observed and synthetic outcomes follow almost an identical trend until 2012, observed outcomes severely drop post-war. This estimation shows that, due to the Donbass war, Donetsk's and Luhansk's average GRP for 2013-2016 decreased by 43\% (4630\$) and 52\% (3326\$), respectively.

\footnotetext{
${ }^{2}$ Kyiv City is Ukraine's capital and its biggest, most affluent agglomeration. It accounts for nearly a quarter of the country's capital investment and its GRP per capita is roughly three times higher than Ukraine's average.
} 


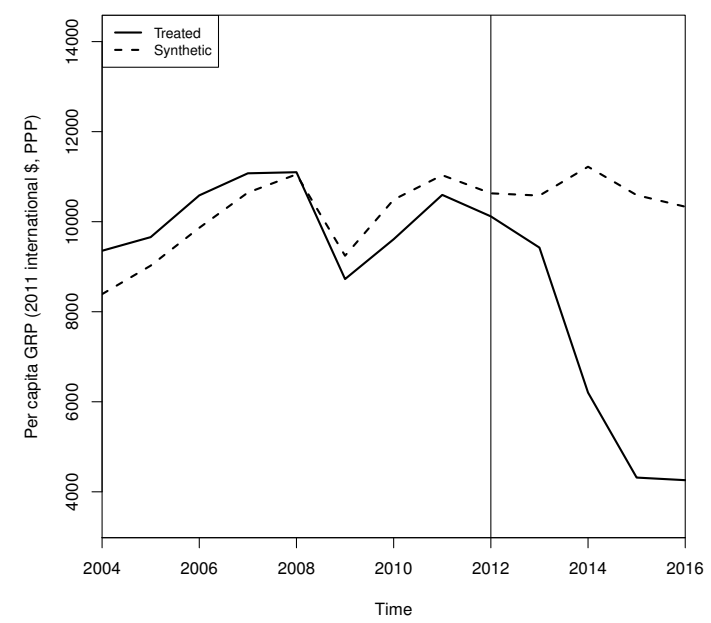

Figure 7. Per capita GRP trends in Donetsk vs. its synthetic counterpart.

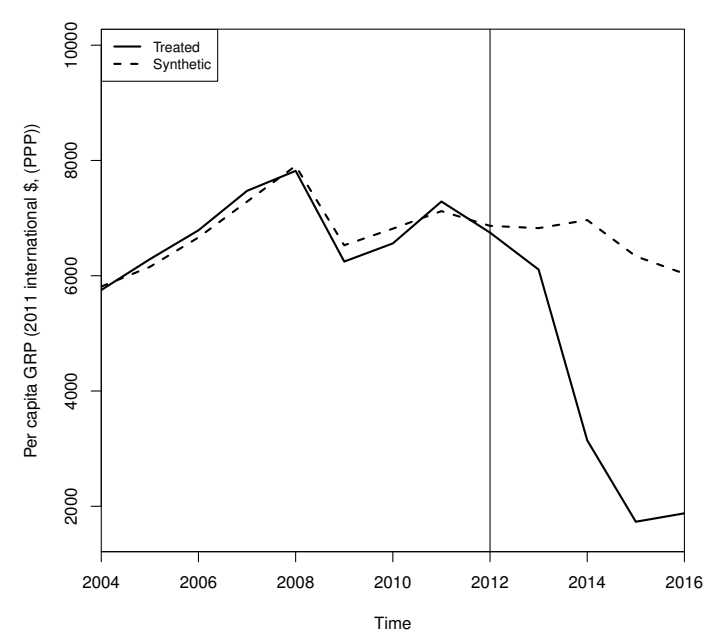

Figure 8. Per capita GRP trends in Luhansk vs. its synthetic counterpart.

Statistical significance of these causal estimates is confirmed by a series of placebo tests (as shown in Fig. 9 below, and Fig. 15 and 16 in the Appendix B).

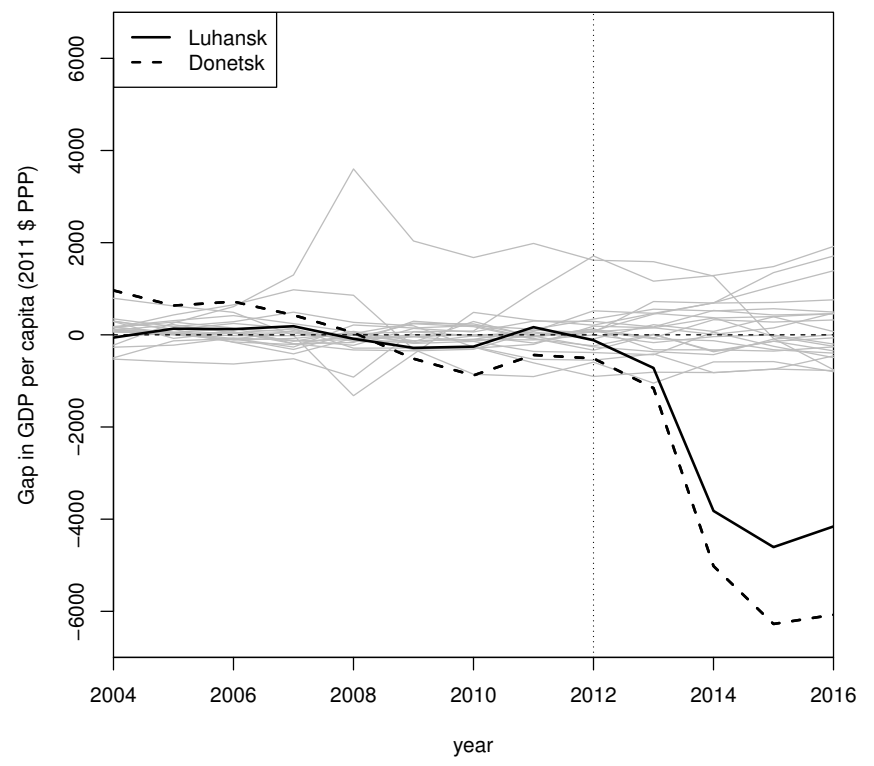

Figure 9. Gaps in per capita GRP in Donetsk, Luhansk and placebo gaps. 


\subsection{Comments on results}

One main limitation to our study is the possible violation of the SCM identifying Stable Unit Treatment Value Assumption (SUTVA). In particular, SUTVA requires the absence of spillover effects of the Donbass war, the treatment, on the GDP of countries in the control group. If SUTVA is violated, the estimated synthetic control built as a linear combination of untreated, though spillovered outcomes would be biased. We identify two main unaccounted-for factors that may cause such spillovers, namely economic sanctions and military expenditures.

Concerning the first, we refer to the economic sanctions imposed on the Russian Federation by the EU in the aftermath of Crimea's annexation in 2014 and the Donbass war. These sanctions may have had an impact not only on the Russian Federation but also on the EU, especially because target and sender countries are economically interdependent and have cooperative political relations (Kaempfer and Lowenber, 2007; Drezner, 1999) $)^{3}$ In light of this, our concern is that the GDP of countries in the control group could be impacted, although indirectly, by these sanctions. However, we argue that this is likely a minor issue for at least three reasons. First, while sanctions affect exports directly, they only indirectly impact the GDP which is more sensitive to other dynamics such as taxation and countries overall performance (Giumelli, 2017). Second, sanctions' effects are shown to be strongest in the very short-run, which indicates that GDP values after 2015 are most likely unaffected (Dizaji and van Bergeijk, 2013). Third, although sanctions' costs are difficult to identify and disentangle from countries' performance, the analysis of export data suggests that only few of our control countries experienced changes in exports that may be attributable to these sanctions. Specifically, a study by Giumelli (2017) finds that, on the one hand, exports of Germany, Italy, France, the Netherlands and Poland seem to be especially hit by the sanctions, with the most severe drop in 2015 compared to 2013. On the other hand, exports of Slovenia, Luxembourg and Romania were affected the least. This brings us to the conclusion that the 2014 sanctions may have had only mild, if any, consequences on the GDP of countries in the control group. Moreover, due

\footnotetext{
${ }^{3}$ In fact, Russia is EU's third largest trade partner, and the EU is Russia's largest one.
} 
to the ambiguity about the direction of the effect in each country, we cannot provide an upper or lower bound for the SC estimator as, e.g., indicated in a similar case by Costalli et al. (2017). Therefore, future research is needed to shed light on the direction and magnitude of sanctions' potential spillovers.

Another source of spillover effects might be changes in military spending in control countries. A strand of literature shows that neighboring states may perceive conflicts as a threat and, thus, increase military expenditures (Smith, 2014; Collier, 2007) which in turn may impact their economic growth (Zielinski et al., 2017; Murdoch and Sandler, 2004). Although similar studies to this commonly assume that indirect spillovers are of negligible magnitude (Costalli et al. 2017; Horiuchi and Mayerson, 2015), we cannot ignore that the Donbass war increased the political instability especially in post-Soviet republics and the Baltic states (Eröss et al., 2016, DeGhett, 2015).

However, also in this case, we believe that changes in military expenditures have only a minor, if any, effect on the results for the following reasons. First, the war's outbreak coincided with multilateral agreements made at the 2014 NATO Summit in which member states were urged to increase their military burden up to 2\% GDP share. As a consequence, countries lagging behind this goal made the most significant investments in this sector with both Latvia and Lithuania increasing their military burdens from $0.9 \%$ in 2013 up to $1.7 \%$ in 2017. The same holds true for Romania and Poland which increased their military burdens over the same period from $1.3 \%$ up to $2 \%$, and from $1.8 \%$ up to $2 \%$, respectively. Thus, the NATO agreement largely explains the variability of military spending over the years 2014-2017 in Eastern Europe. Secondly, in the case of post-Soviet republics, increased military burden occurs according to bilateral military agreements with the Russian Federation, external military investments from Moscow, and modernization programs within the Collective Security Treaty Organization (CSTO) which is also led by Russia (Klein, 2019). Third, although military spending may have indirect effects on GDP growth, the size and the direction of this effect is ambiguous. On the one hand, the literature suggests that increased military expenditure has positive effects on economic growth through increased manufacturing output, inciting technological progress 
and innovation (Barro and Lee, 1994). On the other hand, it can be argued that its effect on investment, capital formation and resource allocation is adverse, indirectly curbing other sectors of the economy and inhibiting long-term economic growth (Knight et al., 1996). Despite the many studies on the topic, there is lack of consensus on the impact of military burden on countries' GDP growth (Herrera and Gentilucci, 2013). As a result, observing no sudden change in the 2014 GDP growth among the control countries, we conclude that the effect of changes in military spending on the donor pool's GDP, if present, is likely negligible. Yet, future research is needed to investigate its magnitude, significance, and spatial dispersion.

\section{Conclusions}

The Donbass war has taken a severe toll on Ukraine, claiming over ten thousand casualties and triggering a severe economic recession. Yet, to the best of our knowledge, there is no empirical evidence on the overall costs incurred by Ukraine as a result of the war. Thus, the goal of this paper is to start filling this gap by quantifying Ukraine's GDP foregone due to the Donbass war.

Results from the counterfactual estimation by the synthetic control method indicate that the Donbass war led to a considerable decline of Ukraine's economy. Namely, we estimate that, due to this war, the country's per capita GDP decreased by $15.1 \%(1438.90 \$)$ on average over the period 2013-2017. Statistical significance of the causal estimates is shown by multiple placebo tests, and robustness is checked by leave-one-out estimations, and confoundedness analyses. In particular, we find that the 2009 gas disputes with Russia and the financial crisis in the same year may lead to overestimated causal effects. As a consequence, the estimated lower-bound of Ukraine's per capita GDP foregone due to the war amounts to $12.7 \%$.

Additionally, we show that the conflict affected the Donbass more severely than the other Ukrainian regions. Over the period 2013-2016, the per capita GRP of the Donbass provinces of Donetsk and Luhansk is found to be, on average, 43\% (4630\$) lower compared to its synthetic counterpart not affected by the strife. This result is in line with 
the estimated causal effects at country-level.

Several interesting issues are still outstanding. First, this paper focuses on quantifying the economic consequences of the conflict on per capita GDP. Although these account for a large part of direct and indirect costs of the war, we do ignore human capital, social, and psychological effects as well as migration dynamics which start to occur in the longer run. Moreover, given the ongoing nature of the conflict at the time of writing, the continuation of this study should be pursued as more data become available. It should be assessed how the costs evolve over time, in particular, weather the estimated destructive effects increase in scope as more workforce and investment flee the state. This knowledge is crucial to mitigate the damaging consequences of the conflict, and target aid and investment more effectively. These issues are under investigation by the authors.

\section{References}

Abadie, A., A. Diamond, and J. Hainmueller (2010). Synthetic control methods for comparative case studies: Estimating the effect of california's tobacco control program. Journal of the American Statistical Association 105(490), 493-505.

Abadie, A. and J. Gardeazabal (2003). The economic costs of conflict: A case study of the Basque country. The American Economic Review 93(1), 113-132.

Ahn, S., Y. Lee, and P. Schmidt (2013). Panel data models with multiple time-varying individual effects. Journal of Econometrics 174(1), 1-14.

Angelovski, D. (2015). Socio-economic impact and needs assessment. Donbass, Ukraine. FAO Report.

Arkhangelsky, D., S. Athey, D. A. Hirshberg, G. W. Imbens, and S. Wager (2019). Synthetic Difference In Differences. ArXiv e-prints working paper (arXiv:1812.09970).

Barro, R. and J.-W. Lee (1994). Sources of economic growth. Carnegie Rochester Conference Series on Public Policy 40(1), 1-46. 
Collier, P. (2007). The Bottom Billion: Why the poorest countries are failing and what can be done about it. New York: Oxford University Press, Inc.

Costalli, S., L. Moretti, and C. Pischedda (2017). The economic costs of civil war: Synthetic counterfactual evidence and the effects of ethnic fractionalization. Journal of Peace Research 54(1), 80-98.

DeGhett, T. (2015). Defense and security: Romania is starting to freak out about Russian designs on Transnistria. Vice News (October 6, 2015, accessed on February 15, 2018).

Dizaji, S. and P. van Bergeijk (2013). Potential early phase success and ultimate failure of economic sanctions: A VAR approach with an application to Iran. Journal of Peace Research 50(6), 721-736.

Drezner, D. (1999). The Sanctions Paradox. New York: Oxford University Press, Inc.

Erőss, A., K. Kóvaly, and P. Tátrai (2016). Effects of the Ukrainian crisis in Transcarpathia: The Hungarian perspective. CMR Working Papers - Center of Migration Research.

Ferman, B. and C. Pinto (2017). Placebo tests for synthetic controls. MPRA Paper No. 78079, University Library of Munich, Germany.

Firpo, S. and V. Possebom (2016). Synthetic control method: Inference, sensitivity analysis and confidence sets.

Gardeazabal, J. (2010). Methods for measuring aggregate costs of conflict. The Oxford Handbook of the Economics of Peace and Conflict, 227-251.

Gates, S. (2012). Development consequences of armed conflict. World Development 40(9), $1713-1722$.

Giumelli, F. (2017). The redistributive impact of restrictive measures on eu members: Winners and losers from imposing sanctions on russia. Journal of Common Market Studies 55(5), 1062-1080. 
Gobillon, L. and T. Magnac (2016). Regional policy evaluation: Interactive fixed effects and synthetic controls. The Review of Economics and Statistics 98(3), 535-551.

Havlik, P. (2014). Economic Consequences of the Ukraine Conflict. The Vienna Institute for International Economic Studies, Policy Notes and Reports 14.

Herrera, R. and E. Gentilucci (2013). Military spending, technical progress, and economic growth: A critical overview on mainstream defense economics. Journal of Innovation Economics and Management 12(2), 13-35.

Horiuchi, Y. and A. Mayerson (2015). The opportunity cost of conflict: Statistically comparing Israel and synthetic Israel. Political Science Research and Methods 3(3), 609618

Kaempfer, W. and A. Lowenber (2007). The political economy of economic sanctions. Handbook of Defense Economics 2, 867-911.

Keynes, J. (1919). The economic consequences of the peace. London: Macmillan.

Klein, M. (2019). Russias military policy in the post-soviet space. SWP Research Paper.

Knight, M., N. Loayzan, and D. Villanuev (1996). The peace dividend: Military expenditure cuts and economic growth. World Bank Policy Research Working Paper.

Koubi, V. (2005). War and economic performance. Journal of Peace Research 42(1), $67-82$.

Lanoszka, A. (2016). Russian hybrid warfare and extended deterrence in eastern Europe. International Affairs 92(1), 175-195.

Marshall, M. G. (2017). Polity IV project: Political regime characteristics and transitions, 1800-2017 (http://www.systemicpeace.org/inscrdata.html).

Monaghan, A. (2016). The 'war' in Russia's 'hybrid warfare'. Parameters 45 (4), 65-74.

Murdoch, J. C. and T. Sandler (2004). Civil wars and economic growth: Spatial dispersion. American Journal of Political Science 48(1), 138-151. 
Rácz, A. (2015). Russia's hybrid war in Ukraine breaking the enemy's ability to resist. The Finnish Institute of International Affairs.

Reisinger, H. and A. Golts (2014). Russia's hybrid warfare: Waging war below the radar of traditional collective defense. The Research Division of the NATO Defense College 105.

Rubin, D. (1974). Estimating causal effects of treatments in randomized and nonrandomized studies. Journal of Educational Psychology 5(5), 688-701.

Seifert, S. and M. Valente (2017). An offer that you can't refuse? Agrimafias and migrant labor on vineyards in southern Italy. DIW Berlin: Discussion Papers 1735.

Smith, R. (2014). The economic costs of military conflict. Journal of Peace Research 51(2), 245-256.

Soares, R. (2006). The welfare cost of violence across countries. Journal of Health Economics 25(5), 821-846.

Stiglitz, J., A. Sen, and J.-P. Fitoussi (2009). The welfare cost of violence across countries. Report by the Commission on the Measurement of Economic Performance and Social Progress.

Walker, S. (2015). Putin admits Russian military presence in Ukraine for the first time. The Guardian (17 December 2015).

Zielinski, R., B. Fordham, and K. Schilde (2017). What goes up, must come down? The asymmetric effects of economic growth and international threat on military spendings. Journal of Peace Research 54(6), 791-805.

\section{Appendix}

\section{A Graphs}

Figure 10 shows the LOO estimations: the solid black line represents Ukraine's observed GDP per capita, dashed black line is the original synthetic Ukraine, and gray lines are 
the LOO synthetic controls.

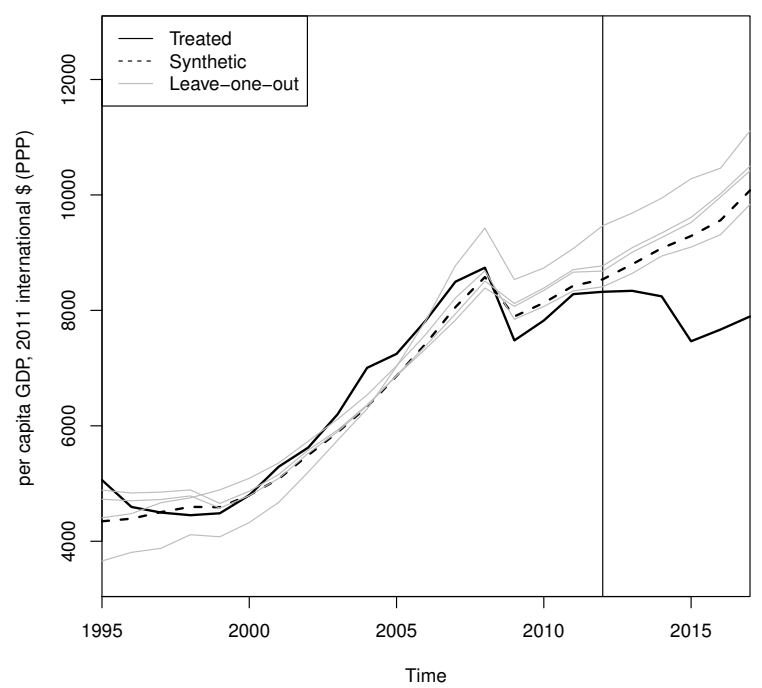

Figure 10. Leave-one-out distribution of synthetic control for Ukraine.

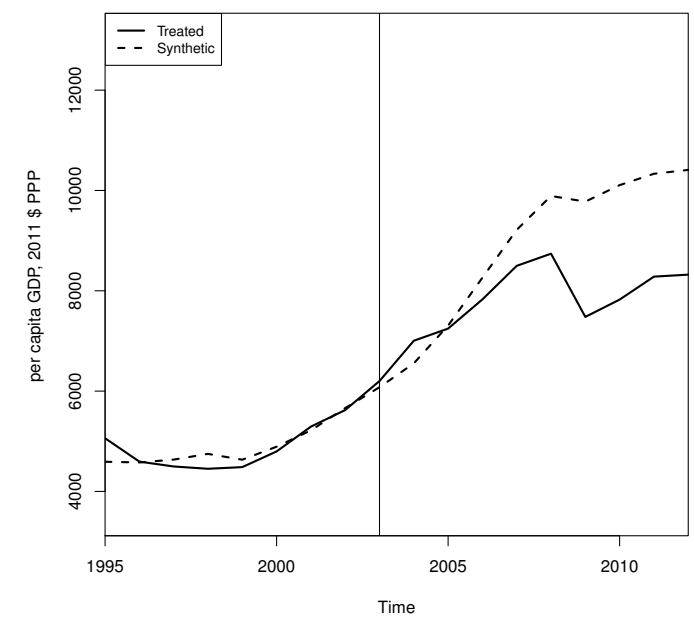

Figure 11. Orange Revolution: per capita GDP trends in Ukraine vs. its synthetic counterpart.

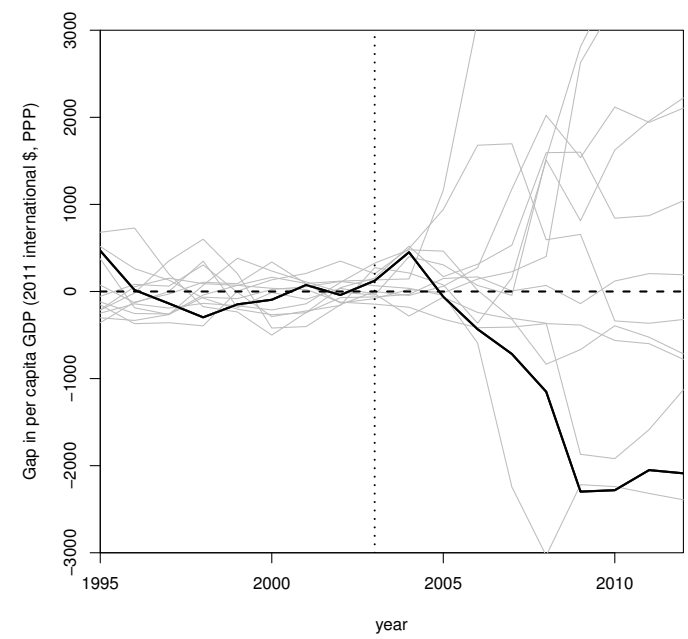

Figure 12. Orange Revolution: gaps in per capita GDP in Ukraine and placebo gaps. 


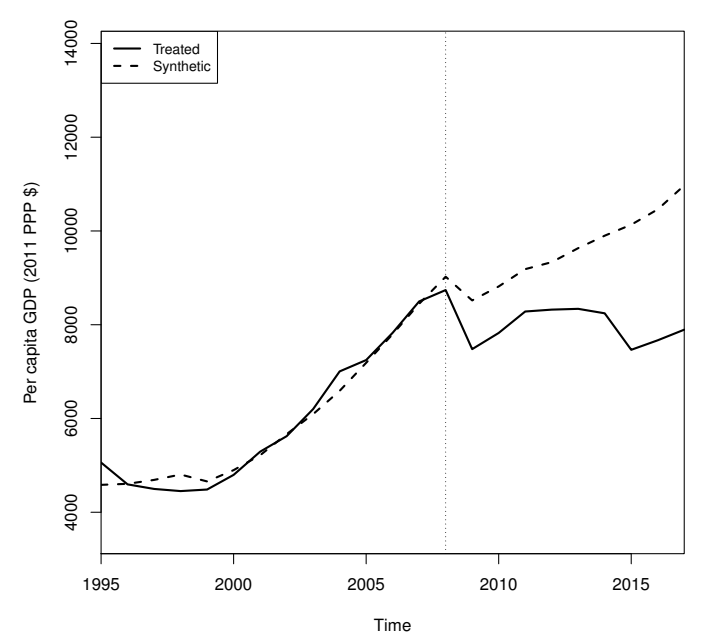

Figure 13. The 2009 gas disputes: Per capita GDP in Ukraine vs. synthetic Ukraine, and causal effects' correction.

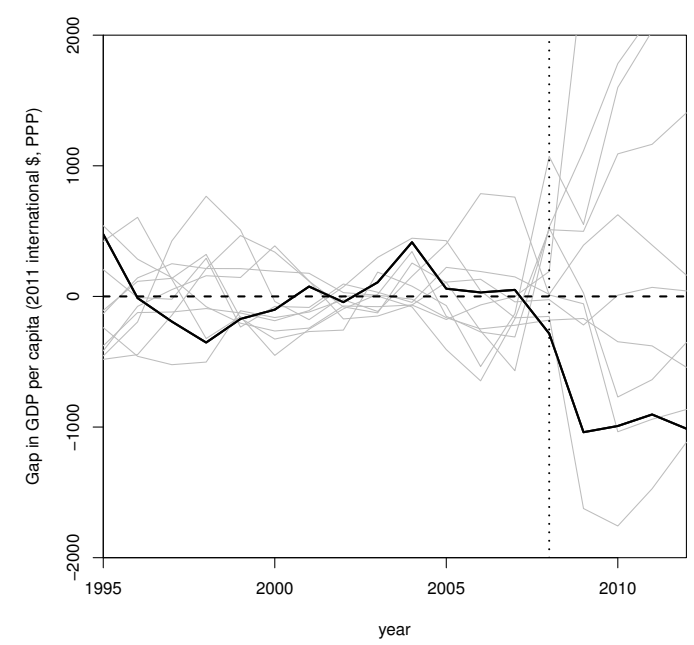

Figure 14. The 2009 gas disputes: Gaps in per capita GDP in Ukraine and placebo gaps.

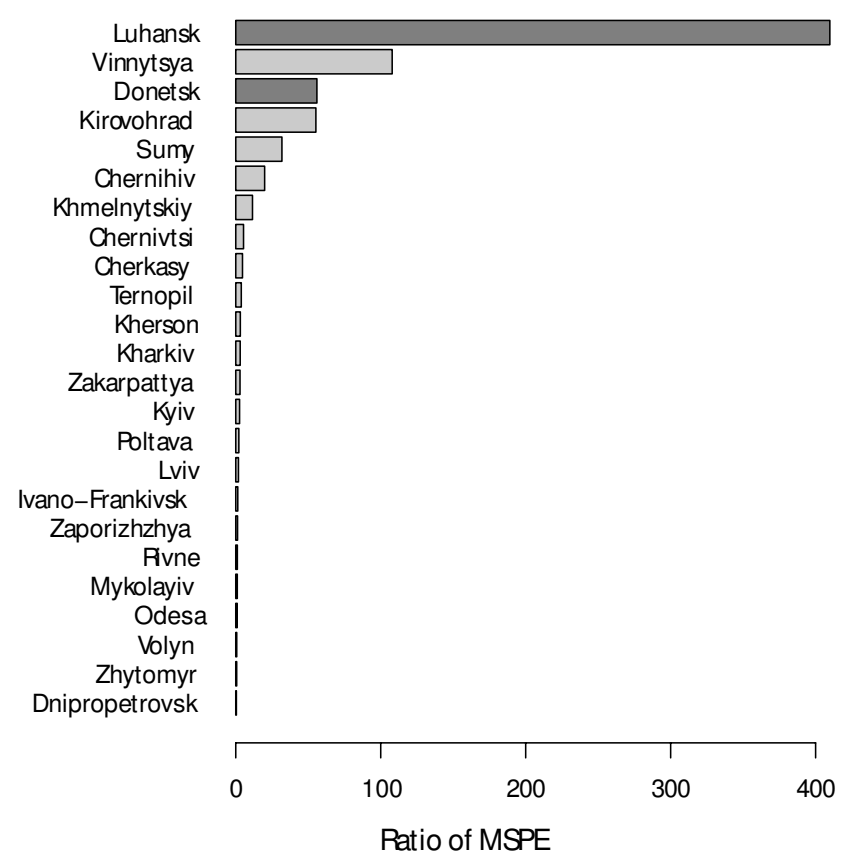

Figure 15. Ratio of mean squared prediction errors in post-war and pre-war period for the regional synthetic control model. 


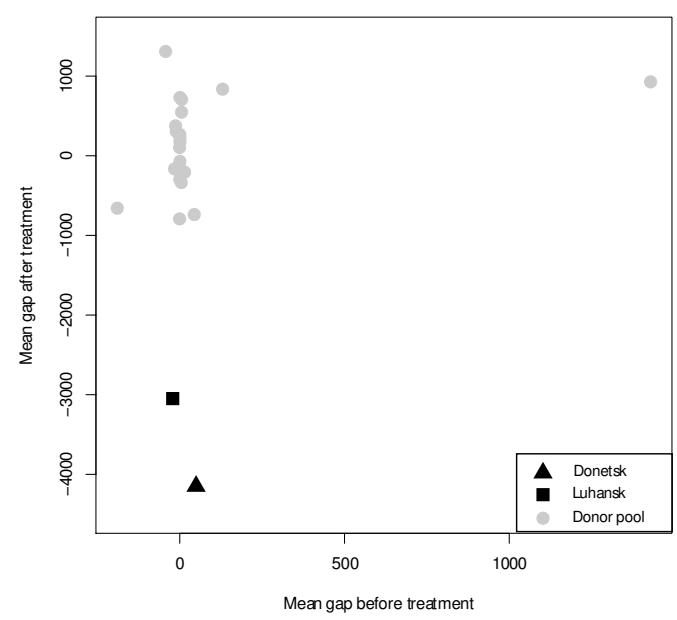

Figure 16. Scatterplot of mean prediction errors in post-war and pre-war period for the regional synthetic control model. Control sample is denoted as donor pool.

\section{B Tables}

\begin{tabular}{ll}
\hline \hline Variable & Description \\
\hline Inflation & Inflation, consumer prices (annual \%) \\
GFCF & Gross fixed capital formation (\% of GDP) \\
Polity & Polity IV Individual Country Regime Trend \\
HDI & Human Development Index \\
TradeDep & Sum of exports and imports with the Russian Federation (\% of GDP) \\
\hline \hline
\end{tabular}

Table B.1. Data description of variables used in the country-level model. Data source: World Bank's World Development Indicators; Marshall (2017).

\begin{tabular}{ll}
\hline \hline Variable & Description \\
\hline Export & Exports of commodities, (thsd. USD) \\
Investment & Capital investment by region \\
& (mln. 2011 international dollars, PPP) \\
Unemployment & Unemployment rate of population (results of a sampling \\
& survey population of economic activity) \\
GRP & Per capita gross regional product \\
& $(2011$ international dollars, PPP) \\
\hline \hline
\end{tabular}

Table B.2. Data description of variables used in regional estimation. Data source: State Statistics Service of Ukraine (http://www.ukrstat.gov.ua). 


\begin{tabular}{cccc}
\hline \hline Year & Rate & Year & Rate \\
\hline 2004 & 0.963 & 2010 & 0.332 \\
2005 & 0.773 & 2011 & 0.291 \\
2006 & 0.673 & 2012 & 0.26 \\
2007 & 0.548 & 2013 & 0.249 \\
2008 & 0.426 & 2014 & 0.223 \\
2009 & 0.377 & 2015 & 0.161 \\
& & 2016 & 0.132 \\
\hline \hline
\end{tabular}

Table B.3. Exchange rates between UAH and international 2011 dollars. Own elaboration based on Ukrainian GDP data obtained from Ukrainian State Statistics Service in UAH and corresponding data obtained from World Bank in international 2011 dollars.

\begin{tabular}{lccccc}
\hline Region & W-Donetsk & W-Luhansk & Region & W-Donetsk & W-Luhansk \\
\hline Dnipropetrovsk & 0.416 & 0.253 & Poltava & 0.575 & 0 \\
Chernivtsi & 0 & 0.426 & Zakarpattya & 0 & 0.025 \\
Zaporizhzhya & 0.001 & 0.136 & Odesa & 0 & 0.159 \\
Volyn & 0 & 0 & Zhytomyr & 0 & 0 \\
Ivano-Frankivsk & 0.001 & 0 & Kyiv & 0.001 & 0 \\
Kirovohrad & 0.001 & 0 & Lviv & 0.001 & 0 \\
Mykolayiv & 0.001 & 0 & Rivne & 0 & 0 \\
Sumy & 0 & 0 & Ternopil & 0 & 0 \\
Kharkiv & 0 & 0 & Kherson & 0 & 0 \\
Khmelnytskiy & 0 & 0 & Cherkasy & 0 & 0 \\
Chernihiv & 0 & 0 & & & \\
\hline \hline
\end{tabular}

Table B.4. Donetsk's and Luhansk's control sample with corresponding weights.

\begin{tabular}{lccc}
\hline \hline Covariate & Treated & Synthetic & Control sample \\
\hline Export & $11,578,745$ & $4,768,440$ & $1,211,371$ \\
Unemployment & $7.94 \%$ & $7.94 \%$ & $8.50 \%$ \\
Investment & 8500 & 5049 & 2441 \\
GRP & 10,091 & 10,041 & 6,014 \\
\hline \hline
\end{tabular}

Table B.5. Donetsk's per capita GRP predictor means. All variables are averaged for 2004-2012. 


\begin{tabular}{lccc}
\hline \hline Covariate & Treated & Synthetic & Control sample \\
\hline Export & $3,702,182$ & 2,896525 & $1,211,371$ \\
Unemployment & $6,9 \%$ & $7,44 \%$ & $8.50 \%$ \\
Invest & 3410.18 & 3410.80 & 2441.06 \\
GRP & $6,773.60$ & $6,794.98$ & 6013.95 \\
\hline \hline
\end{tabular}

Table B.6. Luhansk's per capita GRP predictor means. All variables are averaged over 2004-2012 period.

\begin{tabular}{lcc}
\hline \hline Covariate & $\begin{array}{c}\text { Donetsk } \\
\text { Weight }\end{array}$ & $\begin{array}{c}\text { Luhansk } \\
\text { Weight }\end{array}$ \\
\hline Export & 0 & 0.001 \\
Unemployment & 0.881 & 0.001 \\
Investment & 0 & 0.958 \\
GRP & 0.119 & 0.04 \\
\hline \hline
\end{tabular}

Table B.7. Predictor weights $\mathbf{V}^{*}$ in the regional estimations.

\begin{tabular}{cccc}
\hline \hline Year & Rate & Year & Rate \\
\hline 2004 & 0.963 & 2010 & 0.332 \\
2005 & 0.773 & 2011 & 0.291 \\
2006 & 0.673 & 2012 & 0.26 \\
2007 & 0.548 & 2013 & 0.249 \\
2008 & 0.426 & 2014 & 0.223 \\
2009 & 0.377 & 2015 & 0.161 \\
\hline \hline
\end{tabular}

Table B.8. Exchange rates between UAH and international 2011 dollars. Own elaboration based on Ukrainian GDP data obtained from Ukrainian State Statistics Service in UAH and corresponding data obtained from World Bank in international 2011 dollars. 